\title{
VeSTIBOLOGY
}

\section{Pseudo-spontaneous nystagmus increases Bow and Lean Test accuracy}

\author{
La presenza di nistagmo pseudo-spontaneo incrementa l'accuratezza del Bow \\ and Lean Test
}

\author{
Mario Faralli ${ }^{1}$, Alfredo Di Giovanni ${ }^{1}$, Giacomo Ciacca ${ }^{1}$, Giulia Zambonini ${ }^{1}$, Erica De Bernardo², Vincenzo Marcelli ${ }^{2}$ \\ ${ }_{1}^{1}$ Otorhinolaryngology Clinic, University of Perugia, Perugia, Italy; ${ }^{2}$ A.S.L. Napoli1 Centro, Ospedale del Mare, Naples, Italy
}

\section{SUMMARY}

Object. The aim of this study was to evaluate the effectiveness of the Bow and Lean Test (BLT) based on nystagmus intensity and direction evaluation (NID-BLT) in the diagnosis of benign paroxysmal positional vertigo of the lateral semicircular canal (LSC-BPPV). We hypothesised that the presence of a pseudo-spontaneous nystagmus increases the diagnostic accuracy of the test.

Methods. The BLT was performed in 32 subjects affected by LSC-BPPV.

Results. BLT was positive in 27 cases with a sensitivity of $84.3 \%$ and an accuracy of $70.4 \%$. In other words, it was possible to carry out a BPPV root canal diagnosis (LSC) with BLT in 27 patients, of whom 19 also received a diagnosis of side and form. Pseudo-spontaneous nystagmus was detected in 15 patients, all of whom were BLT positive. In these patients, a clear diagnosis of form and side was also obtained in 14 cases (accuracy 93.3\%). In the 12 patients without pseudo-spontaneous nystagmus and BLT positive, a diagnosis of side and form was reached in 5 cases (accuracy $41.6 \%$ ). The comparison between percentages (Chi square test) showed a significant difference $(\mathrm{p}=0.038)$.

Conclusions. The presence of a pseudo-spontaneous nystagmus, as an expression of more mobile debris within the canal or a more deflectable cupula, increases the accuracy of the BLT.

KEY WORDS: benign paroxysmal positional vertigo, lateral semicircular canal, vestibular system, pseudo-spontaneous nystagmus, Bow and Lean Test

\section{RIASSUNTO}

Obiettivo. Scopo dello studio è stato valutare l'efficacia del Bow and Lean Test (BLT) nella diagnosi di vertigine posizionale parossistica benigna del canale semicircolare laterale (LSC-BPPV). Nello specifico abbiamo ipotizzato che la presenza di nistagmo pseudo-spontaneo potesse incrementare l'accuratezza del BLT.

Metodi. Abbiamo eseguito il BLT in 32 pazienti affetti da LSC-BPPV.

Risultati. Il BLT è risultato positivo, consentendo diagnosi di LSC-BPPV, in 27 casi; inoltre in 19 pazienti è stato possibile identificare il lato affetto e la forma (sensibilità 84,3\%, accuratezza 70,4\%). Quindici dei pazienti presentavano nistagmo pseudo-spontaneo, questi sono risultati tutti positivi al BLT ed è stato inoltre possibile ottenere una diagnosi di forma in 14 casi (accuratezza 93,3\%). Nei 12 pazienti, positivi al BLT, che non presentavano nistagmo pseudo-spontaneo è stato possibile fare diagnosi di lato e forma in 5 casi (accuratezza 41,6\%). Il confronto tra le percentuali (test del Chi quadro) ha mostrato una differenza statisticamente significativa.

Conclusioni. I risultati ottenuti permettono di affermare che la presenza di nistagmo pseudo-spontaneo, espressione di una maggiore mobilità intracanalare degli otoliti o di una più ampia escursione della cupola, incrementa l'accuratezza del BLT.

PAROLE CHIAVE: vertigine posizionale parossistica benigna, canale semicircolare laterale, sistema vestibolare, nistagmo pseudo-spontaneo, Bow and Lean Test
Received: September 24, 2020

Accepted: December 28, 2020

\section{Correspondence}

Mario Faralli

Otorhinolaryngology Clinic, University of Perugia, Perugia, Italy

Tel. +39075 5783236

E-mail: mario.far@hotmail.it

Funding

None.

Conflict of interest

The Authors declare no conflict of interest.

How to cite this article: Faralli M, Di Giovanni A, Ciacca G, et al. Pseudo-spontaneous nystagmus increases Bow and Lean Test accuracy. Acta Otorhinolaryngol Ital 2021;41:270-276. https:// doi.org/10.14639/0392-100X-N1136

(C) Società Italiana di Otorinolaringoiatria e Chirurgia Cervico-Facciale

\section{(c) (1) $(2)$}

This is an open access article distributed in accordance with the CC-BY-NC-ND (Creative Commons Attribution-NonCommercial-NoDerivatives 4.0 International) license. The article can be used by giving appropriate credit and mentioning the license, but only for non-commercial purposes and only in the original version. For further information: https:// creativecommons.org/licenses/by-nc-nd/4.0/deed.en 


\section{Introduction}

Benign paroxysmal positional vertigo (BPPV) represents the most common vestibular disorder. It can affect all ages, although the incidence increases progressively in the elderly. BPPV is about two to three times more common in women than in men ${ }^{1}$. BPPV occurs due to the displacement of otoconia within the fluid-filled semicircular canals of the inner ear, which is capable of inducing significant endolymphatic flows responsible for vertigo crises following head movements ${ }^{2}$. The anamnesis strongly orientates towards a diagnosis which must, in any case, be confirmed by bedside examination. Paroxysmal positional nystagmus, when it respects certain morphological and temporal characteristics, represents the typical semeiological element for diagnosis of BPPV. The most frequent locations of the dislodged otoconia are the ampullary arm of the posterior semicircular Canal (PSC) and the non-ampullary arm of the lateral semicircular canal (LSC) ${ }^{2}$. In particular, LSCBPPV results from the movement of dense particles in the LSC. The diagnostic test is the supine roll test, also called Pagnini-McClure manoeuver ${ }^{3,4}$, showing, in the two positions, a typical horizontal paroxysmal bipositional bidirectional nystagmus which is apogeotropic in case of dense particles adherent to the cupula (cupulolithiasis) or freefloating in the LSC ampullary arm (canalolithiasis) and geotropic in case of dense particles free-floating in the LSC non-ampullary arm (canalolithiasis) ${ }^{2,5,6}$. The identification of the affected ear is fundamental in order to perform the right repositioning manoeuvre. In the apogeotropic form, the nystagmus is more intense when the affected ear is up, since this position provokes a direct (cupulolithiasis) or indirect (canalolithiasis, endolymph-mediated) excitatory deflection of the cupula, according to Ewald's $2^{\text {nd }}$ law. On the contrary, the nystagmus is less intense when the affected ear is down, since this position provokes an inhibitory deflection of the cupula. In the geotropic form, the nystagmus is more intense when the affected ear is down, since this position provokes an indirect, endolymph-mediated excitatory deflection of the cupula, while the nystagmus is less intense with the affected ear up, since this position provokes an indirect, endolymph-mediated inhibitory deflection of the cupula. As a result, the affected ear can be determined as the side showing the less intense nystagmus in the apogeotropic form and the side showing the more intense nystagmus in the geotropic form ${ }^{5,7}$. However, it is sometimes difficult to identify the differences in nystagmus intensity occurring during roll test that lead to diagnosis of side. For this reason, secondary signs and several tests for lateralisation, performed in both erect and supine positions, have been described: "pseudo-spontaneous" nystagmus ${ }^{7,8}$, "null-point" in the pitch plane ${ }^{8,9}$, "bending nystagmus" ${ }^{10}$, "Bow and Lean Choung's Test" "11, "Head Shaking-Induced Nystagmus" (HSIN) ${ }^{8}$, Sitting to Supine positioning Test (SSPT) ${ }^{12-15}$ and null point in supine position ${ }^{9}$. On occasion, the psycho-physical conditions of the patient significantly affect the executability of diagnostic and therapeutic manoeuvers in clinical practice. The need for a diagnosis, even timely in any case, requires the examiner to adhere to a behaviour of minimum stress for the patient, in order to collect useful semeiological information. The Bow and Lean Test (BLT) based on nystagmus intensity and direction evaluation (NID-BLT) ${ }^{16}$ for its dynamic characteristics seems to respond to these needs. The BLT was designed by Choung to evaluate whether pitch movements (flexion and hyperextension) of the head can generate or modify a suggestive nystagmus of LSC-BPPV ${ }^{11}$. The test is performed with the patient seated with the head in axis with the trunk (starting position). In this position, before execution of pitch head movements, horizontal pseudo-spontaneous nystagmus, generated by the slow slide of the dense particles along the LSC, may be present in subjects suffering from LSC-BPPV ${ }^{8}$.

The purpose of this study was qualitative and quantitative analysis of the oculomotor responses obtained with the application of the NID-BLT. For this purpose, a consecutive population of LSC-BPPV patients ascertained by Pagnini-McClure manoeuver was recruited. The sensitivity of the BLT in the diagnosis of LSC-BPPV and its accuracy in identifying the intracanal location of the debris and the affected side were calculated. A comparative assessment in terms of sensitivity and diagnostic accuracy was performed between patients affected from LSC-BPPV with and without spontaneous nystagmus in sitting position before performing BLT. We hypothesised that the presence of a pseudo-spontaneous nystagmus, as an expression of more mobile debris within the canal or a more deflectable cupula, increases the diagnostic accuracy of the BLT.

\section{Materials and methods}

32 consecutive patients suffering from LSC-BPPV without any other associated vestibular disease were enrolled in a prospective study from January 2019 to February 2020. Patients underwent vestibular examination using an infrared video-nystagmoscopic and video-nystagmographic instrument (VNG Ulmer; Synapsys S.A., Marseille, France) to confirm diagnosis of BPPV. Patients suffering from PSCBPPV or Anterior Semicircular Canal (ASC) BPPV were not recruited. Patients were initially selected in accordance with our protocol (see below) in which BPPV was speculated, but not confirmed by bedside examination; patients in 
whom important neurovegetative symptoms prevented the correct execution of diagnostic manoeuvers were excluded.

\section{Study protocol}

132 consecutive patients with suggestive anamnesis for BPPV were initially selected for the study from a population of 290 patients who came to our observation in the period from 1 January 2019 to 28 February 2020. Patients underwent vestibular tests including BLT, Pagnini-McClure and Dix-Hallpike manoeuvers. The reliable diagnosis of LSC-BPPV and PSC-BPPV was ascertained with the Pagnini-McClure and Dix-Hallpike manoeuvers, respectively. Three operators belonging to the ENT Clinic of Perugia were involved in the study with specific vestibular skills. In particular, the first was assigned to the collection of anamnestic data which allowed to formulate the hypothesis of BPPV. The second performed the BLT for searching nystagmus evoked by cupulo-canalolitiasis of LSC. Subsequently, the third operator performed the Pagnini-McClure manoeuver, an indispensable procedure for the definitive diagnosis of LSC-BPPV. The BLT was always performed before Pagnini-McClure manoeuver. It is important to underline the time sequence of the tests, because the PagniniMcClure manoeuver, if performed before, can influence the BLT sensitivity and results. The second and third operators operated in a double-blind fashion.

\section{$B L T$}

Before the BLT was performed, the patient was observed in two or three preliminary positions:

A) Primary position: the patient, seated with the head in axis with the trunk, is assessed for a horizontal pseudospontaneous nystagmus.

B) Null point position: the so-called null point position must be sought with a slow pitch movement of the head (or LSC tilt) forward to determine the disappearance of the spontaneous nystagmus. When the LSC lies on a horizontal plane, in fact, the spontaneous sliding of the particles disappears and so does the nystagmus.

C) Starting position: once the null point is identified, which is slightly different in each subject due to the inevitable anatomical differences, we bow the head of $30^{\circ}$ with respect to the null point itself and wait for about $30 \mathrm{sec}$ (or wait for the disappearance of nystagmus if evoked).

The starting position can be reached directly, excluding the null point position, in the case that pseudo-spontaneous nystagmus was not detected in the primary position.

The next phase is the proper NID-BLT test:

$1^{\text {st }}$ step (Lean): from the starting position the head is leant $60^{\circ}$ backward, and the nystagmus is evaluated. The head should be held in this position for $30 \mathrm{sec}$. $2^{\text {nd }}$ step (Bow): the head is bowed $60^{\circ}$ forward and the nystagmus intensity assessed again. The head should be held in this position for $30 \mathrm{sec}$.

The test is based on assumption that the nystagmus intensity, in the two BLT positions, may be equally compared only if the magnitude of the LSC tilt (or head pitch) is identical. Only in this case can one be certain that the dense particles run through the affected LSC at the same speed and that the difference in nystagmus intensity is solely due to Ewald's $2^{\text {nd }}$ law ${ }^{16}$.

The different "nystagmus intensity" in the bow and in the lean positions was used to differentiate a geotropic form from an apogeotropic one. "Direction nystagmus" evaluation allows identification of the affected side when associated with the "intensity nystagmus" evaluation.

\section{Data collection and statistical evaluation}

The sensitivity and diagnostic accuracy of BLT in patients suffering from LSC-BPPV with or without spontaneous nystagmus in the primary head position was calculated. A sensitive test was intended to be able to provide, on the basis of the semeiological findings that emerged during the examination, a diagnosis exclusively of root canal location. An accurate test was intended to provide a diagnosis not only of root canal location, but also of intra-canal location of debris (geotropic form, apogeotropic form) and the affected side. The comparison between percentages was made by chi-square test. Differences with $\mathrm{p}<0.05$ were considered to be statistically significant.

The authors assert that all procedures contributing to this work comply with the ethical standards of the relevant national and institutional guidelines on human experimentation and with the Helsinki Declaration of 1975, as revised in 2008. Informed consent was obtained from all participants in the study.

\section{Results}

Of the 132 patients initially selected based on their history, 16 were excluded as the diagnostic manoeuvers (PagniniMcClure and Dix-Hallpike) did not evoke paroxysmal positional nystagmus. In all these patients, BLT did not evoke nystagmus. In addition, 11 patients with a history suggestive of BPPV could not complete the bedside examination due to onset of significant autonomic symptoms. A further 8 patients were excluded as they presented down beating nystagmus to the diagnostic procedures, which led to a hypothesis of an apogeotropic variant of PSC-BPPV ${ }^{17}$ or ASC-BPPV. Additionally, 61 patients affected by PSCBPPV were not enrolled. Thirty-six patients were affected by LSC-BPPV. In 4 (3 apogeotropic, 1 geotropic) of the 
36 patients with LSC-BPPV it was not possible to make a side diagnosis, as no significant differences in the intensity of the nystagmus evoked at the two Pagnini-McClure manoeuvers were detectable. Therefore, 32 patients with LSC-BPPV were definitively recruited in the study. In all these cases, the Pagnini-McClure manoeuver allowed with reasonable certainty a diagnosis of root canal involvement (LSC) and affected side (19 right, 13 left) and intracanal localisation (22 non-ampullary: geotropic form, 10 ampullary arm: apogeotropic form). The BLT was positive in 27 cases with a sensitivity of $84.3 \%$. In 5 patients (patients 5-7-13-26-29), BLT did not evoke any nystagmus (Tab. I).
The diagnostic accuracy was $70.4 \%$. In other words, it was possible to carry out a BPPV root canal diagnosis (LSC) with BLT in 27 patients, of whom 19 also received a diagnosis of side and form (Tab. I). In the other 8 patients, the BLT did not show clinically appreciable differences in the intensity of the inverted nystagmus, evoked by the two investigated head positions, in 6 cases (patients 4-10-1215-20-31). In the remaining 2 patients, the direction and the intensity of the inverted nystagmus was in opposition with the clinical findings from Pagnini-McClure manouever (patients 9-18) (Tab. I). Pseudo-spontaneous nystagmus was detected in 15 patients (patients 1-2-3-6-8-11-14-16-

Table I. Semeiological findings in 32 patient affected by LSC-BPPV.

\begin{tabular}{|c|c|c|c|c|c|c|c|c|c|}
\hline Patient & Arm & Form & Side & $\begin{array}{c}\text { Bow } \\
\text { (ny direction) }\end{array}$ & $\begin{array}{c}\text { Lean } \\
\text { (ny direction) }\end{array}$ & $\begin{array}{c}\text { Bow } \\
\text { (ny intensity) }\end{array}$ & $\begin{array}{c}\text { Lean } \\
\text { (ny intensity) }\end{array}$ & $\begin{array}{l}\text { Sensivity } \\
\text { (BLT) }\end{array}$ & $\begin{array}{c}\text { Accurancy } \\
\text { (BLT) }\end{array}$ \\
\hline 1 & Non ampullary & Geo & Right & Right & Left & +++ & + & Yes & Yes \\
\hline 2 & Non ampullary & Geo & Right & Right & Left & +++ & + & Yes & Yes \\
\hline 3 & Ampullary & Apogeo & Right & Left & Right & + & +++ & Yes & Yes \\
\hline 4 & Non ampullary & Geo & Left & Left & Right & ++ & ++ & Yes & No \\
\hline 5 & Ampullary & Apogeo & Right & Absent & Absent & Absent & Absent & No & No \\
\hline 6 & Non ampullary & Geo & Right & Right & Left & +++ & + & Yes & Yes \\
\hline 7 & Non ampullary & Geo & Left & Absent & Absent & Absent & Absent & No & No \\
\hline 8 & Non ampullary & Geo & Right & Right & Left & +++ & + & Yes & Yes \\
\hline 9 & Ampullary & Apogeo & Left & Left & Right & +++ & + & Yes & No \\
\hline 10 & Non ampullary & Geo & Left & Left & Right & ++ & ++ & Yes & No \\
\hline 11 & Non ampullary & Geo & Right & Right & Left & +++ & + & Yes & Yes \\
\hline 12 & Ampullary & Apogeo & Right & Left & Right & ++ & ++ & Yes & No \\
\hline 13 & Non ampullary & Geo & Left & Absent & Absent & Absent & Absent & No & No \\
\hline 14 & Non ampullary & Geo & Right & Right & Left & +++ & + & Yes & Yes \\
\hline 15 & Non ampullary & Geo & Left & Left & Right & ++ & ++ & Yes & No \\
\hline 16 & Non ampullary & Geo & Right & Right & Left & +++ & + & Yes & Yes \\
\hline 17 & Ampullary & Apogeo & Left & Right & Left & + & +++ & Yes & Yes \\
\hline 18 & Ampullary & Apogeo & Right & Right & Left & +++ & + & Yes & No \\
\hline 19 & Non ampullary & Geo & Right & Right & Left & +++ & + & Yes & Yes \\
\hline 20 & Non ampullary & Geo & Left & Left & Right & ++ & ++ & Yes & No \\
\hline 21 & Non ampullary & Geo & Left & Left & Right & +++ & + & Yes & Yes \\
\hline 22 & Ampullary & Apogeo & Right & Left & Right & + & +++ & Yes & Yes \\
\hline 23 & Non ampullary & Geo & Right & Right & Left & +++ & + & Yes & Yes \\
\hline 24 & Ampullary & Apogeo & Left & Right & Left & + & +++ & Yes & Yes \\
\hline 25 & Non ampullary & Geo & Right & Right & Left & +++ & + & Yes & Yes \\
\hline 26 & Non ampullary & Geo & Right & Absent & Absent & Absent & Absent & No & No \\
\hline 27 & Non ampullary & Geo & Right & Right & Left & +++ & + & Yes & Yes \\
\hline 28 & Ampullary & Apogeo & Left & Right & Left & + & +++ & Yes & Yes \\
\hline 29 & Ampullary & Apogeo & Right & Absent & Absent & Absent & Absent & No & No \\
\hline 30 & Non ampullary & Geo & Left & Left & Right & +++ & + & Yes & Yes \\
\hline 31 & Non ampullary & Geo & Right & Right & Left & ++ & ++ & Yes & No \\
\hline 32 & Non ampullary & Geo & Left & Left & Right & +++ & + & Yes & Yes \\
\hline
\end{tabular}


20-22-23-24-25-30-32), all BLT positive and none of the 5 cases of LSC-BPPV with negative BLT (Tab. II). The presence of a pseudo-spontaneous nystagmus therefore implies a sensitivity and specificity of BLT of 100\%. In 17 patients without pseudo-spontaneous nystagmus, BLT was positive in 12 cases $(70.6 \%)$. The comparison between the two groups of patients showed a statistically significant increase in BLT sensitivity in the presence of pseudo-spontaneous nystagmus. Regarding the diagnostic accuracy of BLT in presence of pseudo-spontaneous nystagmus, the data are as follows: In the 15 patients with pseudo-spontaneous nystagmus and positive for BLT, a clear diagnosis of form and side was also obtained in 14 cases (accuracy 93.3\%), obviously confirmed at the subsequent Pagnini-McClure manouever. In the 12 patients without pseudo-spontaneous nystagmus and positive BLT, a clear diagnosis of form and side was reached in 5 cases (accuracy 41.6\%). The comparison between percentages (Chi square test) showed a significant difference $(\mathrm{p}=0.038)($ Tab. II).

\section{Discussion}

The BLT is a simple method that may help to determine the affected ear in cases of LSC-BPPV. The limitation is

Table II. Sensitivity and accuracy of the BLT in LSC-BPPV patient with and without pseudo-spontaneous nystagmus.

\begin{tabular}{|c|c|c|c|c|}
\hline Patient & $\begin{array}{l}\text { Diagnosis LSC-PPV } \\
\text { (Pagnini-McClure) }\end{array}$ & $\begin{array}{l}\text { Pseudo-spontaneous } \\
\text { ny }\end{array}$ & $\begin{array}{l}\text { Sensivity } \\
\text { (BLT) }\end{array}$ & $\begin{array}{l}\text { Accurancy } \\
\text { (BLT) }\end{array}$ \\
\hline 1 & Right geotropic & Yes & Yes & Yes \\
\hline 2 & Right geotropic & Yes & Yes & Yes \\
\hline 3 & Right apogeotropic & Yes & Yes & Yes \\
\hline 4 & Left geotropic & No & Yes & No \\
\hline 5 & Right apogeotropic & No & No & - \\
\hline 6 & Right geotropic & Yes & Yes & Yes \\
\hline 7 & Left geotropic & No & No & - \\
\hline 8 & Right geotropic & Yes & Yes & Yes \\
\hline 9 & Left apogeotropic & No & Yes & No \\
\hline 10 & Left geotropic & No & Yes & No \\
\hline 11 & Right geotropic & Yes & Yes & Yes \\
\hline 12 & Right apogeotropic & No & Yes & No \\
\hline 13 & Left geotropic & No & No & - \\
\hline 14 & Right geotropic & Yes & Yes & Yes \\
\hline 15 & Left geotropic & No & Yes & No \\
\hline 16 & Right geotropic & Yes & Yes & Yes \\
\hline 17 & Left apogeotropic & No & Yes & Yes \\
\hline 18 & Right apogeotropic & No & Yes & No \\
\hline 19 & Right geotropic & No & Yes & Yes \\
\hline 20 & Left geotropic & Yes & Yes & No \\
\hline 21 & Left geotropic & No & Yes & Yes \\
\hline 22 & Right apogeotropic & Yes & Yes & Yes \\
\hline 23 & Right geotropic & Yes & Yes & Yes \\
\hline 24 & Left apogeotropic & Yes & Yes & Yes \\
\hline 25 & Right geotropic & Yes & Yes & Yes \\
\hline 26 & Right geotropic & No & No & - \\
\hline 27 & Right geotropic & No & Yes & Yes \\
\hline 28 & Left apogeotropic & No & Yes & Yes \\
\hline 29 & Right apogeotropic & No & No & - \\
\hline 30 & Left geotropic & Yes & Yes & Yes \\
\hline 31 & Right geotropic & No & Yes & No \\
\hline 32 & Left geotropic & Yes & Yes & Yes \\
\hline
\end{tabular}


represented by the need to always integrate the test with the Pagnini-McClure manoeuvre in order to know a priori which variant (geotropic vs. apogeotropic) the patient is suffering from. Nystagmus intensity and direction evaluation overcome this limitation, providing information without necessarily having to resort to other tests ${ }^{16}$. Based on semeiological findings, in both forms the direction of the more intense nystagmus points to the affected side, while the different nystagmus intensity in the bow and in the lean position allow us to differentiate a geotropic form from an apogeotropic one. In our study the NID-BLT was effective in identifying the form and the side in the $70.4 \%$ of patients, a slightly lower value than that reported in a previous study $(76 \%)^{16}$. Several reasons can explain the lack of identification in some cases. First, a very minimal difference between the intensities in the two positions was found, even during video-nystagmographic recordings. Another limitation is the occurrence of mixed forms in which some otoconia are adherent to the cupula, but others are free-floating within the semicircular canal. Finally, different accelerations in the canal can be generated by unequal amplitude in flexion and extension, and thus the different nystagmus intensity may also be due to a slight difference in head angle. The main data emerging from our study is the significant increase in the accuracy of the BLT when pseudo-spontaneous nystagmus was observed in the primary position of the head, before performing the diagnostic procedures. Such horizontal nystagmus, which may be present in subjects suffering from LSC-BPPV, when present, is generated by the slow slide of dense particles along the LSC. Since the LSC is superiorly inclined by $30^{\circ}$ forward relative to the horizontal plane, it behaves as a natural and true inclined plane along which the dense particles slowly slide, resulting in either an excitatory (dense particles adherent to the cupula or free-floating in the ampullary arm) or inhibitory (dense particles in non-ampullary arm) deflection of the cupula and nystagmus ${ }^{16}$. The reason why the aforementioned semeiological data is associated with a greater accuracy of the BLT is not easy to understand. It is conceivable that debris, more endowed with higher mobilisation capacity for intrinsic root canal factors, are more affected by gravitational effects and, therefore, more predisposed to spontaneously induce endolymphatic flows and significant ampullary deflections responsible for pseudo-spontaneous nystagmus before performing the text. These dynamic characteristics may influence the following responses evoked at BLT. In the presence of floating particles, whose inertia is able to overcome the resistance of opposing forces by exploiting only the inclination of the LSC plane, the energy applied at the beginning of the pitch movements would be largely used to induce endolymphatic flows generated by the new spatial relationships between gravitational vector and LSC. On the contrary, in the absence of nystagmus, where a lower spontaneous mobility of the particles is conceivable, the energy applied to the pitch movements would initially be dissipated, in part, to overcome the counter-resistance forces. In all probability, these effects would be greater at the beginning of the first diagnostic positioning in lean (or bow). The amount of stimulus and the extent of the responses evoked by the two pitch movements of the head could prove unequal and lead to less accuracy in the interpretation of the NID-BLT. This model, proposed for canalolithiasis (ampullary and non-ampullary arm) appears, however, less convincing to explain the spontaneous nystagmus and the relative greater accuracy of BLT in cupulolithiasis. An accurate BLT represents an undoubted therapeutic advantage. The ability to diagnose the form (geotropic vs apogeotropic) and the side of the BPPV by BLT allows to correctly orient $\mathrm{Gu}$ foni's manoeuver ${ }^{18}$ towards the most suitable decubitus for the repositioning procedure, without the diagnostic aid provided by the Pagnini-McClure manoeuver. This advantage appears further confirmed by the situation in which neurovegetative symptoms, possibly present, represent an aggravating condition for the patient's stress and limiting the performance of traditional diagnostic manoeuvers. The last consideration regards the appropriateness of resorting to additional measures such as gentle lateral head rotations in sitting position (low frequencies) to either side or the vibratory stimulus (high frequencies) that is capable of promoting the mobility of the particles and the appearance of a pseudo-spontaneous nystagmus that was previously absent. The BLT is a valid clinical approach, even in patients who do not show pseudo-spontaneous nystagmus. Despite the low accuracy, the test is easy to perform and well tolerated. Undoubtedly, the induction of this semeiological data may be useful in determining an increase in the accuracy of the BLT in cases in which the anamnesis strongly orientates towards a diagnosis of BPPV and the presence of neurovegetative symptoms, or physical limitations, advise against the execution of traditional diagnostic manoeuvers.

\section{Conclusions}

Our study found that the presence of a pseudo-spontaneous nystagmus, as an expression of more mobile debris within the canal or a more deflectable cupula, increases the diagnostic accuracy of the BLT. Additional measures such as gentle lateral head rotations to either side before BLT execution, capable of promoting the mobility of the particles and the appearance of a pseudo-spontaneous nystagmus previously absent are recommended. 


\section{References}

1 Bruintjes TD, van der Zaag-Loonen HJ, Eggelmeijer F, et al. The prevalence of benign paroxysmal positional vertigo in patients with osteoporosis. Eur Arch Otorhinolaryngol 2018;275:3083-3086. https://doi.org/10.1007/s00405-018-5164-4

2 Brandt T, Steddin S. Current view of the mechanism of benign paroxysmal positioning vertigo: cupulolithiasis or canalolithiasis? J Vestib Res 1993;3:373-82.

3 McClure A. Lateral canal BPV. J Otolaryngol 1985;14:30-35.

4 Pagnini P, Nuti D, Vannucchi P. Benign paroxysmal vertigo of the horizontal canal. ORL J Otorhinolaryngol Relat Spec 1989;51:161170. https://doi.org/10.1159/000276052

5 Brandt T. Benign paroxysmal positional vertigo. In: Brandt T, editor Vertigo: its multisensory syndrome. Second Edition. Berlin: SpringerVerlag; 1999. pp. 269-279.

6 Baloh RW, Jacobson KM, Honrubia V. Horizontal semicircular variant of benign positional vertigo. Neurology 1993;43:2542-2549. https://doi.org/10.1212/wnl.43.12.2542

7 Asprella-Libonati G. Diagnostic and treatment strategy of lateral semicircular canal canalolithiasis. Acta Otorhinolaryngol Ital 2005;25:277-283.

8 Asprella-Libonati G. Pseudo-spontaneous nystagmus: a new sign to diagnose the affected side in lateral semicircular canal benign paroxysmal positional vertigo. Acta Otorhinolaryngol Ital 2008;28:73-78.

9 Bissdorff AR, Debatisse D. Localizing signs in positional vertigo due to lateral cupulolithiasis. Neurology 2001;57:1085-1088. https://doi. org/10.1212/wnl.57.6.1085

10 Lee S-H, Choi K-D, Jeong S-H, et al. Nystagmus during neck flexion in the pitch plane in benign paroxysmal positional vertigo involv- ing the horizontal canal. J Neurol Sci 2007;256:75-80 https://doi. org/10.1016/j.jns.2007.02.026

11 Choung Y-H, Shin YR, Kahng H, et al. "Bow and Lean Test" to determine the affected ear of horizontal canal benign paroxysmal positional vertigo. Laryngoscope 2006;116:1776-1781. https://doi. org/10.1097/01.mlg.0000231291.44818.be

12 Nuti D, Vannucchi P, Pagnini P. Benign paroxysmal positional vertigo of the horizontal canal: a form of canalolithiasis with variable clinical features. J Vest Res 1996;6:173-184. https://doi.org/10.3233/ VES-1996-6303

13 Nuti D, Vannucchi P, Pagnini P. Lateral canal BPPV: which is the affected side? Audiol Med 2005;3:16-20. https://doi. org/10.1080/16513860510028275

14 Han BI, Oh HJ, Kim JS. Nystagmus while recumbent in horizontal canal benign paroxysmal positional vertigo. Neurology 2006;66:706710. https://doi.org/10.1212/01.wnl.0000201184.69134.23

15 Koo JW, Moon IJ, Shim WS, et al. Value of lying-down nystagmus in the lateralization of horizontal semicircular benign paroxysmal positional vertigo. Otol Neurotol 2006;27:367-371. https://doi. org/10.1097/00129492-200604000-00013

16 Marcelli V. Nystagmus intensity and direction in bow and lean test: an aid to diagnosis of lateral semicircular canal benign paroxysmal positional vertigo. Acta Otorhinolaryngol Ital 2016;36:520-526. https:// doi.org/10.14639/0392-100X-795

17 Vannucchi P, Pecci R, Giannoni B, et al. Apogeotropic posterior semicircular canal benign paroxysmal positional vertigo: some clinical and therapeutic considerations. Audiol Res 2015;5:130. https://doi. org/10.4081/audiores.2015.130.

18 Gufoni M, Mastrosimone L. Trattamento con manovra di riposizionamento per la canalolitiasi orizzontale. Acta Otorhinolaryngol Ital 1998; 18:363-367. 